\title{
Eliminación de ácido clorogénico durante el procesado acuoso de las almendras de girasol
}

\author{
Por H. Domínguez, M.J. Núñez y J.M. Lema \\ Departamento de Ingeniería Química. Universidad de Santiago de Compostela \\ Avda. de las Ciencias, s/n. 15706-Santiago de Compostela
}

\section{RESUMEN}

Eliminación de ácido clorogénico durante el procesado acuoso de las almendras de girasol.

Se estudió el efecto de la incorporación de etapas específicas de eliminación de compuestos fenólicos durante el procesado acuoso de girasol para obtención de aceite de buena calidad y producción simultánea de harina de color claro. Durante el procesado acuoso se alcanza el $88 \%$ de eliminación de ácido clorogénico, valor superado por los dos métodos alternativos propuestos, siendo la difusión con agua (a elevada temperatura durante períodos cortos) de compuestos fenólicos de la pasta desgrasada la que proporciona mayor eficacia $(98.6 \%$ ), aunque la solubilidad de la proteína se reduce un $9 \%$. Si se aplica una etapa de difusión a partir de almendras a la mitad, el contenido de ácido clorogénico se logra reducir en $93.7 \%$, sin afectar a la solubilidad de la proteína. La digestibilidad resulta mejorada tras la aplicación de cualquiera de los dos procesos de difusión propuestos.

PALABRAS-CLAVE: Aceite - Acido clorogénico - Extracción acuosa Girasol - Harina.

\section{SUMMARY}

Chlorogenic acid removal during aqueous processing of sunflower kernels

The effect of incorporating specific stages to remove phenolic compounds during aqueous processing of sunflower, to obtain oil of good quality and meal of light color was studied. The aqueous process removes $88 \%$ of the chlorogenic acid initially present in the kernels; this value is overpassed with the two modifications proposed, being the diffusion of the deffated paste with hot water at short intervals the most efficient $(98.6 \%)$, although protein solubility is reduced in $9 \%$. If the diffusion step is performed from half kernels, the chlorogenic acid content is reduced in $93.7 \%$, without affecting protein solubility. Protein digestibility is enhanced after applying any of the two proposed diffusion steps. flower.

KEY-WORDS: Aqueous extraction - Chlorogenic acid - Meal - Oil - Sun

\section{INTRODUCCION}

La harina de girasol descascarado es rica en proteína y no presenta sustancias antinutritivas o tóxicas. La proteína, aunque deficiente en lisina (solamente contiene un $52 \%$ de la lisina presente en la proteína de soja), posee una gran proporción de aminoácidos azufrados (metionina y cisteína) y es de excelente calidad para consumo animal y humano, aunque sus usos potenciales están limitados por la presencia de compuestos fenólicos. Estos componentes, principalmente el ácido clorogénico, son responsables (junto con los azúcares reductores) del color oscuro de los alimentos procesados (Sabir et al., 1974 b). La presencia de compuestos fenólicos afecta a la calidad de la proteína de girasol reduciendo la digestibilidad, alterando las propiedades organolépticas y funcionales, reduciendo la estabilidad de los productos y el valor nutritivo de la proteína (Lin et al., 1974; Sosulski, 1979; Shamanthaka y Sastry, 1990).

\section{Compuestos fenólicos en las semillas de girasol}

Leung et al., (1981) comprobaron en diferentes variedades de girasol por cromatografía y espectroscopía de masas que los compuestos fenólicos presentes son: cafeico, clorogénico, p-hidroxibenzoico, p-cumárico, cinámico, m-hidroxibenzoico, vaníllico y siríngico. Se han identificado también ácidos transcinámico, isoferúlico y sinápico (Sabir et al., 1974a; Dreher et al., 1983). El contenido total de compuestos fenólicos en girasol oscila entre $3-4 \%(p / p)$ de las almendras desgrasadas, de los cuales el $78.6 \%$ es soluble y el $21.4 \%$ está ligado a las proteínas (Bau et al., 1983). Las cáscaras contienen un $4.55 \%$ de compuestos fenólicos, siendo el $0.14 \%$ compuestos fenólicos libres, no enlazados a proteínas. El ácido clorogénico, éster del quínico y del cafeico constituye con este último un $70 \%$ de todos los compuestos fenólicos, y se encuentra en varias formas isoméricas; posee sabor ácido y astringente (Nagel et al., 1987), y es causante del color verdoso o marrón. El contenido en ácido clorogénico y cafeico disminuye durante el almacenado, aunque a temperaturas elevadas lo hace en menor grado. El contenido de ácido quínico es constante en las distintas zonas de la semilla y el de cafeico y clorogénico es diferente en los extremos de la semilla y en el centro (Pomenta y Burns, 1971).

\section{Efectos sobre el color y el sabor}

A medida que el pH aumenta de neutro a básico, el 
color progresa desde el tono amarillo claro al verde y al marrón, coloración que se debe a la oxidación de los polifenólicos. Estos compuestos oxidados se enlazan fácilmente con las proteínas, lo que reduce la calidad de las mismas, puesto que el nuevo compuesto no puede ser metabolizado; además una modificación posterior del pH no permite lavar y eliminar esta coloración, que puede usarse como parámetro indicativo de la digestibilidad del producto (Elías et al., 1979).

\section{Interacción de los compuestos fenólicos con proteínas}

La existencia de distintos grupos en las cadenas laterales de los aminoácidos hace que las proteínas presenten una importante tendencia a interactuar con los otros componentes presentes en las semillas. Los compuestos fenólicos libres se combinan reversiblemente con las proteínas mediante enlaces hidrógeno, iónico e interacciones hidrofóbicas entre los grupos hidroxílicos del compuesto fenólico y los grupos peptídicos de la proteína (Hurrell y Finot, 1985) .

\section{Eliminación del ácido clorogénico de las semillas de girasol}

Para evitar la oxidación del ácido clorogénico fenólico y la consiguiente formación de enlaces irreversibles con las proteínas es necesaria la extracción de este compuesto. El interés de los procesos de extracción de los compuestos fenólicos se justifica no sólo desde el punto de vista industrial, también por las interesantes posibilidades de empleo que la proteína de girasol representa en la alimentación humana.

La eliminación del ácido clorogénico puede realizarse a partir de almendras desgrasadas o previamente al proceso de extracción del aceite, en cuyo caso resulta más operativo emplear almendras troceadas, puesto que facilita la agitación de la suspensión (por su menor viscosidad), la separación por filtración (no requiere centrifugación) y la facilidad de secado de las almendras (frente al liofilizado para evitar cambios adversos de color y propiedades). Puesto que la eliminación de sustancias fenólicas con disolventes orgánicos es incompleta, y la proteína (concentrados y aislados) resulta desnaturalizada en mayor o menor grado, se han propuesto distintos métodos para eliminar el ácido clorogénico con disoluciones acuosas a $\mathrm{pH}$ ácido para obtener productos con sabor suave y color claro, evitando pérdidas de proteína por solubilización y para alcanzar la máxima solubilidad del ácido clorogénico (Sodini y Canella, 1977; Lanzani et al., 1983). En medio ácido se maximiza la extracción, pues se debilita la interacción proteínas-fenoles y aumenta la solubilidad de estos últimos.

Empleando almendras troceadas sin desgrasar, la eliminación de la membrana permite disminuir los niveles iniciales de clorogénico desde 3.1 a $2 \mathrm{~g} / 100 \mathrm{~g}$ de harina, indicando que la mayor parte de este compuesto está en las porciones externas de la almendra, próximas a la membrana. El flujo de disolvente no afecta sensiblemente a la velocidad de difusión, siendo la temperatura y la eliminación de la membrana los factores más influyentes. Las altas temperaturas favorecen la eliminación casi total del ácido, pero la proteína obtenida suele presentar menor solubilidad, aunque en métodos como el propuesto por Lanzani et al., (1979), en el que se emplea agua a $100^{\circ} \mathrm{C}$ para eliminar el ácido clorogénico no se modifica el índice de solubilidad de la proteína si el período de contacto de la harina con el disolvente a altas temperaturas se limita a 10 segundos. La extracción de compuestos fenólicos a $60^{\circ} \mathrm{C}$, aunque más lenta e incompleta que a $80^{\circ} \mathrm{C}$, permite obtener un producto de color blanco y tras $120 \mathrm{~min}$ se elimina el $87 \%$; a $80^{\circ} \mathrm{C}$, en 60 min se elimina el $90 \%$ a costa de mayor desnaturalización de la proteína, lo que desaconseja su implantación comercial (Sosulski et al., 1973).

Los procesos de difusión utilizan grandes cantidades de agua, y las soluciones diluídas resultantes representan un serio problema por las corrientes residuales que generan. Sosulski et al., (1973) proponen una concentración por evaporación, ultrafiltración u ósmosis reversa hasta un $50 \%$, para utilización del subproducto en alimentación animal o como sustrato de fermentaciones.

\section{Proceso acuoso}

Los procesos convencionales de extracción de aceites de semillas presentan un alto rendimiento de extracción de aceite, pero requieren un equipo costoso, presentan alto grado de peligrosidad por las grandes cantidades de disolventes utilizados y efectos desfavorables sobre la calidad de los productos finales, por las elevadas temperaturas que se alcanzan en algunas etapas. Entre las posibles alternativas figura la extracción con otros disolventes: agua, alcoholes o sus mezclas acuosas, aldehídos, cetonas y gases supercríticos (Hron et al., 1982; Johnson y Lusas, 1983).

Los procesos acuosos representan una innovación en la tecnología extractiva de semillas oleaginosas para la producción de aceite y también de harinas, concentrados o aislados proteicos (Cruz, 1990), lo que por métodos convencionales requeriría una primera etapa de extracción de aceite y una posterior de compuestos solubles no proteicos. A pesar de que el agua es un mal disolvente del aceite, es un sistema útil para cualquier semilla y para muchos frutos procesados habitualmente para extracción de aceites: cacahuetes (Rhee et al., 1972), soja (Lawhon et al., 1981), algodón, girasol (Lanzani et al., 1983; Hagenmaier, 1974), semilla de palma (Kim, 1989), coco (Hagenmaier et al., 1973), aguacate (Lanzani et al., 1986). Entre las ventajas que ofrecen estas alternativas acuosas se pueden citar: reducción de costes de inversión y operación, por el menor tamaño de la planta frente a una de extracción por disolventes, mayor seguridad operacional y ambiental, al disminuir el riesgo de incendios y explosiones, no presentar riesgos de toxicidad, permitir mayor flexibilidad de operación, ya que las puestas en marcha y las paradas son más seguras, facilitando la operación discontinua, y posibilidad de obtener harina libre de compuestos indeseables. Los inconvenientes respecto a los 
procesos convencionales serían la menor eficiencia en la eliminación de aceite, cuya recuperación requiere un proceso de deemulsificación, menor estabilidad durante el almacenaje de los productos proteicos debido al mayor contenido graso, mayor gasto energético en centrifugación para separar las fases y mayor consumo en energía de secado y evaporación; además precisan de mayor higiene para evitar la contaminación microbiana .

\section{OBJETIVOS}

Una vez expuestas las ventajas que puede suponer el proceso acuoso, se pretende aplicar esta tecnología al procesado de semillas de girasol, con el fin de extraer simultáneamente el aceite y eliminar compuestos fenólicos de la harina. Se emplearon tres formas de operación, que se corresponden con distintas modificaciones del proceso acuoso para eliminación de compuestos fenólicos. El primer método consiste en el procesado acuoso de las almendras de girasol molidas para la extracción del aceite y la obtención simultánea de productos proteicos (a); en el segundo se propone la eliminación por difusión a partir de almendras troceadas a la mitad, a las que una vez secas y molidas se puede aplicar el proceso acuoso de eliminación de aceite y producción de proteína (b). El tercero se realiza sobre harina desgrasada y debido a que el método que se pretende utilizar no elimina totalmente el aceite se realizó un proceso de difusión aplicado a la harina desgrasada (c).

\section{MATERIALES Y METODOS}

\section{Materiales}

A lo largo de este trabajo se emplearon semillas de girasol descascaradas comerciales, cuyo contenido graso es de $63 \%(p / p)$ en base seca. La composición de las almendras desgrasadas con hexano a temperatura ambiente se resume en la Tabla I.

Tabla I

Caracterización de las almendras desgrasadas

\begin{tabular}{lc}
\hline \multicolumn{1}{c}{ Composición } & $\%$ p/p, b.s.d. \\
\hline Proteína (N - 6;25) & 55.0 \\
F.N.D. & 15.5 \\
F.A.D. & 8.8 \\
Lignina & 3.2 \\
Cenizas & 7.0 \\
Ac. clorogénico & 3.5 \\
${ }^{*}$ Az. totales & 6.8 \\
${ }^{*}$ Az. reductores & 1.8 \\
Otros & 12.2 \\
Características & \\
Prot. soluble (pH=9, \%) & 89.2 \\
Digestibilidad (C.D.A., \%) & 81.1 \\
Lisina disp. (mg/16 mg N) & 3.3. \\
\hline
\end{tabular}

*Extraídos con alcohol.

\section{Métodos}

Los análisis de humedad, cenizas, contenido graso, fibras detergentes F.N.D. (fibra neutro detergente: celulosa + hemicelulosa + lignina) y FAD (fibra ácido detergente: celulosa + lignina) se determinaron según los métodos oficiales de análisis (AOAC, Helrich Ed. 1990). Se empleó el factor 6.25 para calcular la proteína total a partir del contenido en N, analizado por micro Kjeldahl. Las muestras desgrasadas y molidas se extrajeron con alcohol al $80 \%$ para extraer los azúcares, determinándose los azúcares totales utilizando sulfato de hidracina en $\mathrm{H}_{2} \mathrm{SO}_{4}$, los reductores por el método del ácido DNS, empleando en ambos glucosa como standard.

El contenido en ácido clorogénico en el producto sólido se determinó extrayendo con una disolución etanol:agua al $50 \%$ en una relación $1: 80(\mathrm{p} / \mathrm{v})$ de una suspensión de harina desgrasada; se agita a temperatura ambiente durante $30 \mathrm{~min}$, se filtra a vacío y reextrae el residuo sólido, repitiendo el proceso 2 veces más. Se mide entonces la absorbancia a $330 \mathrm{~nm}$ en la mezcla de los sobrenadantes obtenidos, frente a un blanco del disolvente empleado para la extracción. La lisina disponible se determinó por el método del TNBS (James y Ryley, 1986). Los análisis de digestibilidad de la harina se llevaron a cabo con el ensayo in vitro propuesto por Hsu et al., (1977). El porcentaje de proteína soluble se analiza dispersando la muestra molida en una solución $0.2 \mathrm{M}$ de $\mathrm{NaCl}$, hasta un $1 \%(\mathrm{p} / \mathrm{v})$ a $\mathrm{pH} 9$, se agita $2 \mathrm{~h}$ a $20-25^{\circ} \mathrm{C}$, manteniendo el valor deseado de $\mathrm{pH}$, se separa por centrifugación y se recoge el sobrenadante, determinando el contenido proteico en solución. La proteína soluble se calcula como fracción de la proteína total en el sobrenadante. Para la presencia de compuestos fenólicos residuales en la harina se utilizó el método visual de Sosulski et al., (1972), basado en la complejación de proteínas con los compuestos fenólicos para formar productos coloreados a pH básico. Se hace una suspensión de 1:200 p/v de harina en agua destilada y se ajusta el $\mathrm{pH}$ a 10 por adición de álcali diluído. Se deja 24 horas antes de observar la intensidad del color verdoso o marrón debido al ácido clorogénico.

El índice de acidez se determinó por el método colorimétrico de Lowry y Tinsley, (1976), basado en la determinación de la solubilidad de los jabones de Cu en función de la longitud de la cadena, empleando el reactivo acetato cúprico-piridina (disolución acuosa de acetato cúprico $5 \%$ $(\mathrm{p} / \mathrm{v})$, con piridina para ajustar el $\mathrm{pH}$ a 6.0-6.2). A la muestra (con menos de $3.5 \mathrm{mg}$ de ácidos grasos volátiles, A.G.V.) se añaden $5.0 \mathrm{~mL}$ de benceno, se agita y se añaden $0.4 \mathrm{~mL}$ del reactivo acetato cúprico-piridina, agitando la mezcla bifásica durante 2 min. Tras centrifugar se lee la absorbancia de la capa superior a $715 \mathrm{~nm}$ con benceno como referencia, empleando una recta patrón con ácido oleico en cloroformo.

Para la determinación del contenido en fosfolípidos se empleó una modificación del método propuesto por Raheja et al., (1973), empleándose una disolución cromogénica (con $\mathrm{Sn} \mathrm{Cl}_{2}$ ), que reacciona con el fósforo formando un complejo azul. A la muestra (1-10 $\mu \mathrm{g}$ de $\mathrm{P})$ se añaden 0.4 
$\mathrm{mL}$ de cloroformo y $0.1 \mathrm{~mL}$ de disolución cromogénica y se homogeneiza; se ponen los tubos de ensayo en un baño de agua hirviendo durante $1 \mathrm{~min}$. Se elimina el disolvente con nitrógeno, se añaden $5.0 \mathrm{~mL}$ de cloroformo y se mezcla, se deja reposar 30 min y se lee la absorbancia (en la capa inferior de cloroformo) a $710 \mathrm{~nm}$ frente a un blanco con $0.4 \mathrm{~mL}$ cloroformo y $0.1 \mathrm{~mL}$ de solución cromogénica, empleando como patrón una disolución de fosfatidilcolina en cloroformo.

El índice de peróxidos, medido como meq de $\mathrm{O}_{2} / \mathrm{kg}$ aceite, se calcula a partir del iodo liberado por oxidación del ioduro potásico, puesto que las sustancias que oxidan este compuesto son peróxidos o productos similares de oxidación de la grasa; el índice obtenido cuantifica en una primera aproximación los peróxidos de la grasa. A la muestra de aceite se añaden $3.0 \mathrm{~mL}$ de ácido acético-cloroformo $(3: 2, \mathrm{v} / \mathrm{v})$ y se percola con $\mathrm{N}_{2}$ durante $2 \mathrm{~min}$. Se adicionan $0.08 \mathrm{~mL}$ de la solución de $1.2 \mathrm{~g}$ de $\mathrm{Kl} / \mathrm{mL}$ de agua destilada (ha de prepararse al hacer la determinación), purgando con $\mathrm{N}_{2} 30$ segundos. Se tapa y deja en la oscuridad durante $1 \mathrm{~h}$ exactamente. Transcurrido este tiempo, se diluye con $7.0 \mathrm{~mL}$ de la solución de acetato de cadmio $0.5 \%$, se tapa y agita. Se centrifuga a $5.000 \mathrm{rpm}$ durante $15 \mathrm{~min}$, eliminando cuidadosamente el sobrenadante y leyendo la absorbancia a $350 \mathrm{~nm}$ frente a la solución de acetato de cadmio como referencia. Para realizar el calibrado se utilizó como patrón una disolución $0.2 \mathrm{mM}$ de $\mathrm{KIO}_{3}$ en acetato de cadmio acuoso $0.5 \%$.

El número de saponificación expresa el peso en mg de hidróxido potásico necesario para saponificar $1 \mathrm{~g}$ de grasa (calculado por un método volumétrico) (AOAC 920.160; UNE 55.012).

\section{Experimental}

La eliminación del aceite por procesos acuosos y la producción simultánea de concentrados proteicos supone el batido en medio ácido de las semillas molidas, una posterior centrifugación para separar la fase sólida y las líquidas y el acondicionado de cada una de ellas. Las condiciones de operación se seleccionaron en base a los criterios que seguidamente se exponen:

Proceso de batido. Las semillas se mantienen agitadas en un incubador orbital a 200 rpm, para lograr un adecuado contacto entre las fases y favorecer la transferencia de materia. El pH durante el proceso de batido se mantiene en el rango 4.5-5. Aunque el rendimiento en aceite cuando se realiza el batido a temperaturas de 60 y $70^{\circ} \mathrm{C}$ mejora sensiblemente, parámetros de calidad como la acidez o el contenido en peróxidos se ven seriamente afectados en estas condiciones (Lanzani et al., 1983). Por ello se eligió una temperatura moderada, $50{ }^{\circ} \mathrm{C}$, que aunque menos favorable para la extractabilidad del aceite es más adecuada para mantener la calidad de los productos.

El procedimiento experimental llevado a cabo es el que se indica en la Fig. 1. Se señalan en zona sombreada las etapas específicas de eliminación de compuestos fenólicos sobre el procedimiento básico que consiste únicamente en la extracción acuosa. Los tres procedimientos empleados en este trabajo permiten la eliminación de compuestos fenólicos en diferentes etapas del proceso:

a) Proceso de extracción acuoso. Una vez descascaradas las semillas, las almendras se muelen hasta un tamaño inferior a $2 \mathrm{~mm}$, realizando el molido de modo intermitente, procurando no someter al material a un sobrecalentamiento durante el proceso. El tamaño de partícula, que no afecta la solubilidad de la proteína (Flemming y Sosulski, 1977), se redujo para favorecer la eliminación del aceite. Los compuestos fenólicos se extraen durante el batido y se eliminan durante la separación de fases sólidolíquido.

b) Proceso continuo de difusión en almendras cortadas transversalmente a la mitad. Este método permite extraer eficazmente el ácido clorogénico de las almendras (Sosulski et al., 1973). El empleo de almendras troceadas facilita la eliminación de las membranas, aumentando la velocidad del proceso, ya que aquellas, aún con bajo contenido en clorogénico, impiden la difusión del que contiene la almendra, distribuído principalmente en las zonas externas de la misma. Se aplica el proceso de difusión, empleando una disolución de $\mathrm{HCl} 0.01 \mathrm{~N}$, en una relación disolvente:almendra de 120:1 durante 2 h, con la agitación suficiente para mantener la suspensión en continuo movimiento. Así se favorece no sólo la difusión por el mejor

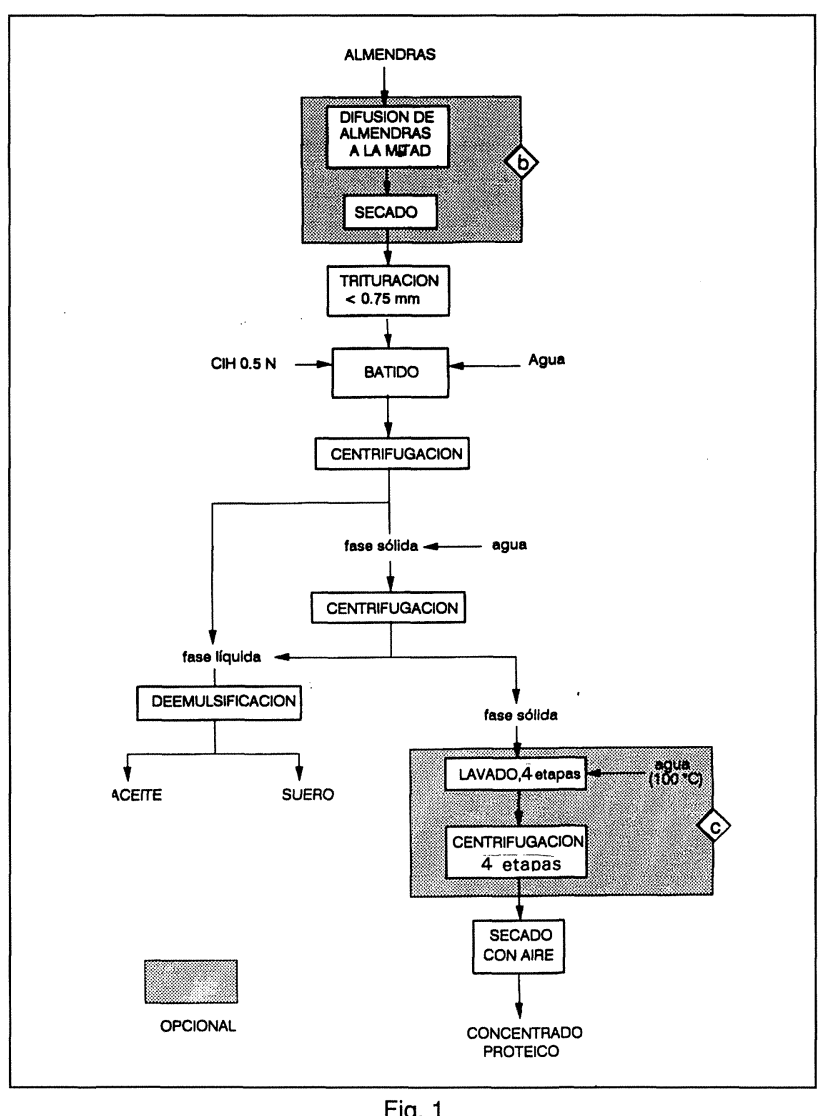

Proceso experimental desarrollado para la extracción acuosa del aceite de girasol. Las etapas específicas de eliminación de compuestos fenólicos se señalan en zona sombreada. 
contacto entre las fases, sino que también se eliminan las membranas, que una vez separadas de las almendras se pueden retirar de la superficie a la que ascienden por flotación.

c) Difusión en 4 etapas en harina molida tras el proceso de extracción acuoso. La aplicación de esta estrategia permite eliminar la práctica totalidad del ácido clorogénico de las almendras molidas desgrasadas (Lanzani et al., 1979), provenientes del proceso de extracción acuoso a. Las almendras molidas procedentes de estas etapas se ponen en contacto con agua a $100^{\circ} \mathrm{C}$ durante 10 segundos, durante los cuales se agita vigorosamente la suspensión, que una vez enfriada a $25-30^{\circ} \mathrm{C}$ se centrifuga de nuevo para eliminar en la fase acuosa los compuestos fenólicos y azúcares. El volumen de agua a $100^{\circ} \mathrm{C}$ añadida en cada una de las etapas es de 25 veces el peso inicial de muestra antes de la aplicación del proceso acuoso. Este proceso se repite cuatro veces, número suficiente de etapas para eliminar cuantitativamente el ácido clorogénico.

\section{RESULTADOS Y DISCUSION}

\section{Relación disolvente:almendra y tamaño de partícula}

Las mejores condiciones para realizar el proceso (relación disolvente:almendra y tamaño de partícula) se definen en función de la extractabilidad del aceite en la fase líquida, medida como diferencia del contenido total de aceite de las almendras con el residual en el producto sólido (por análisis en Soxhlet). Para este fin se realizó un batido de las muestras con diferentes relaciones disolvente:almendra durante $1 \mathrm{~h}$ a $50^{\circ} \mathrm{C}$ y $200 \mathrm{rpm}$ a pH 4.5. La separación de fases se realizó por centrifugación a 10.000 rpm durante 20 min, realizándose una redisolución del residuo sólido en la misma relación disolvente:almendra que durante el batido y centrifugación. Se emplearon relaciones entre 5 y 25 vol de disolvente/g de almendras y tres tamaños: mayor de $1 \mathrm{~mm}$, entre $0.75 \mathrm{~mm}$ y $1 \mathrm{~mm}$, y menor de $0.75 \mathrm{~mm}$. No se emplearon tamaños menores por la dificultad que supone el apelmazamiento de las partículas durante el tamizado. La Figura 2 muestra el efecto sobre la extractabilidad del aceite para diferentes tamaños de partícula y relaciones disolvente:almendra. Aunque la diferencia no es notable, para una relación de $10(\mathrm{v} / \mathrm{p})$ se obtiene una mayor eliminación de aceite que para valores superiores; por ello se fija este valor para los experimentos posteriores. Los sólidos obtenidos tras la primera etapa de centrifugación se resuspenden y agitan en una relación agua:almendra 1:5. Esta reducción en la proporción de agua añadida facilita el proceso de deemulsificación posterior para recuperar el aceite.

Aunque la reducción del tamaño de partícula en el rango estudiado no origina grandes diferencias entre los valores examinados, se aprecia una leve mejoría en el porcentaje de eliminación de aceite con la reducción de tamaño de partícula, debido a la mayor destrucción de las paredes celulares y a la mayor facilidad de extracción del aceite por un mejor contacto agua:semillas.

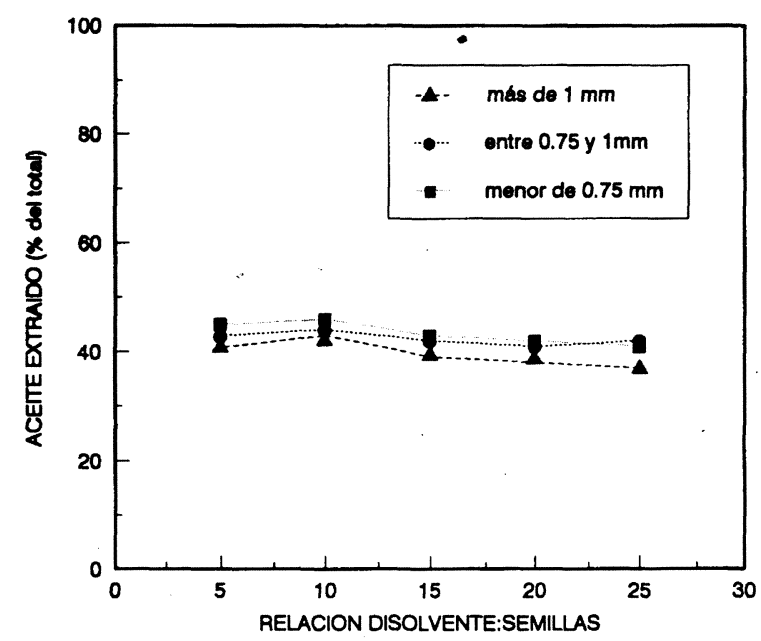

Fig. 2

Efecto de la relación disolvente: semillas para diferentes tamaños de partícula sobre el rendimiento de extracción de aceite durante el procesado acuoso de girasol.

El porcentaje de aceite extraído $(\approx 40-45 \%)$ es del orden del indicado por otros autores. Hagenmaier (1974), trabajando en condiciones similares, con centrifugación discontinua a pH entre 4 y 5 obtiene porcentajes de extracción del $30 \%$ con semillas enteras de un tamaño $0.84 \mathrm{~mm}$, con 10 volúmenes de disolvente por unidad de peso de semillas, frente al $42 \%$ en almendras molidas de tamaño de partícula menor de $0.75 \mathrm{~mm}$ en este trabajo. Lanzani et a., (1975), obtienen también resultados similares cuando emplean centrifugación discontinua. Ambos autores, sin embargo, alcanzan porcentajes de eliminación del $80 \%$, con otros sistemas de centrifugación o en planta piloto. EI empleo de centrífuga discontinua de laboratorio no es, por tanto, un sistema totalmente eficaz. Kim ( 1989) justifica la capacidad limitada de este sistema de separación por el corto recorrido medio del aceite. Otra razón que justifica el bajo porcentaje de aceite extraído es la no aplicación de una etapa previa de acondicionamiento térmico de las semillas (Marek et al., 1990).

Sin embargo, y a pesar de la no idoneidad del sistema de separación, el proceso se revela como un método adecuado para estudiar la eliminación de los compuestos fenólicos de la harina.

\section{Incorporación de una etapa de eliminación de compuestos fenólicos}

La aplicación de las modificaciones descritas hace que el proceso sea significativamente diferente en uno y otro caso. La difusión tanto a partir de almendras cortadas a la mitad a $60^{\circ} \mathrm{C}$ como de las almendras molidas a $100^{\circ} \mathrm{C}$, puede provocar la eliminación no sólo de compuestos fenó- 
licos, sino también la pérdida de proteína solubilizada, a pesar de que se emplea el pH de mínima solubilidad de la proteína de girasol (4.5-5).

El proceso $b$, que trata las almendras cortadas a la mitad, permite mayor recuperación de proteína por la eliminación casi total de las membranas durante la difusiónextracción de ácido clorogénico y la separación completa tras el proceso de secado. Puesto que las membranas constituyen un $2-3 \%$ de la almendra, su eliminación contribuye a reducir la porción fibrosa, aumentando la proteica.

\section{Características de los productos obtenidos}

Los productos resultantes de los procesos a, b y c, se analizaron con el fin de conocer el efecto del tratamiento enzimático sobre los principales parámetros de calidad .

Aceite. Se siguió el método indicado por Lawhon et al., (1981) para romper la emulsión aceite-agua en el líquido obtenido. Se procedió a enriquecer progresivamente la emulsión en fase oleosa, añadiendo el aceite recuperado al centrifugar pequeñas porciones. La Tabla II resume las condiciones experimentales que se mantuvieron durante el proceso.

Tabla II

Condiciones para la recuperación del aceite de la emulsión obtenida por el método acuoso (Lawhon et al., 1981)

\begin{tabular}{|c|c|}
\hline Parámetros & Condiciones \\
\hline Nivel de humedad permisible & 20 \% (máximo 23\%) \\
\hline $\mathrm{pH}$ & 4.5 (rango 4-6) \\
\hline Modo de agitación & Vigorosa \\
\hline Velocidad y tiempo de agitación & $\begin{array}{l}\text { Lenta } \\
1-3 \text { durante minutos }\end{array}$ \\
\hline $\begin{array}{l}\text { Velocidad y tiempo } \\
\text { de centrifugación }\end{array}$ & $\begin{array}{l}1000 \mathrm{rpm} \\
\text { o mayor durante } 1-3 \mathrm{~min}\end{array}$ \\
\hline Temperatura & $40^{\circ} \mathrm{C}$ o mayor \\
\hline
\end{tabular}

Los análisis realizados al aceite obtenido por los procedimientos estudiados se indican en la Tabla III, que permite comparar las propiedades del aceite extraído en sistemas acuosos, siguiendo diferentes métodos de operación.

El grado de acidez -medido como porcentaje de ácidos grasos libres considerados como oleico- del aceite obtenido en los procesos $b$ y $c$ es mayor que en el procedente del proceso a. En los dos primeros las muestras se someten a una temperatura elevada: $60^{\circ} \mathrm{C}$ durante $2 \mathrm{~h}$ en el proceso b y $100^{\circ} \mathrm{C}$ durante 4 etapas de $10 \mathrm{~s}$ en el proceso $\mathrm{c}$, resultando en este último caso menos afectada la calidad del aceite, debido a los cortos tiempos de exposición a las condiciones desfavorables. El contenido en fósforo, medido como fosfolípidos, se reduce, con relación al proceso acuoso a, cuando se extraen los compuestos fenólicos a partir de almendras a la mitad (b), mientras que aumenta si se parte de harina molida (c).
El elevado valor del número de peróxidos en los procesos a, b y c se justifica por la no aplicación previa de un proceso de acondicionamiento térmico. Los valores obtenidos son similares en todos los procesos, ligeramente superiores para el b y c, pero siempre inferiores a los establecidos como máximos (10 meq $\mathrm{O}_{2} / \mathrm{kg}$ ).

Tabla III

Comparación de algunas de las principales

características del aceite obtenido en los distintos procesos empleados para la eliminación de ácido clorogénico

\begin{tabular}{lccc}
\hline Características & Proceso a & Proceso b & Proceso c \\
\hline Acidez total (\% oleico) & 0.79 & 1.23 & 1.03 \\
Fósforo $(\mathrm{ppm})$ & 5.89 & 4.15 & 6.26 \\
Peróxidos $(\mathrm{meq} / \mathrm{kg})$ & 5.27 & 5.50 & 5.76 \\
Saponificación $(\mathrm{mg} \mathrm{KOH} / \mathrm{g})$ & 186 & 186 & 184 \\
\hline
\end{tabular}

Proceso a: Proceso acuoso (sin etapa de eliminación de comp. fenólicos)

Proceso $b$ : Difusión de almendras cortadas a la mitad

Proceso c: Difusión de almendras molidas ya extraídas

Harina. Las características del producto proteico obtenido una vez eliminado el aceite y secado con aire (que reduce la humedad desde $60-70 \%$ tras la centrifugación hasta un 7-8\%) se presentan en la Tabla IV. En cuanto a las características del producto proteico, el contenido en proteína es bajo, no alcanza el $70 \%$ con ninguno de los procedimientos empleados, debido a que no se ha realizado una etapa de lavado posterior para purificarlo, y a la baja eficacia de eliminación de aceite con el sistema de separación empleado, indicada ya previamente.

Acido clorogénico. El proceso acuoso, designado por a, permite reducir el contenido de ácido clorogénico desde el $3.5 \%(p / p)$ inicial en las almendras hasta un $0.41 \%$, lo que supone un $88 \%$ de eliminación. Las harinas obtenidas por los procesos b y c para la eliminación de ácido clorogénico, antes y después de la extracción acuosa respectivamente, contienen menos polifenoles, medidos como ácido clorogénico. La difusión en almendras cortadas, seguida de la extracción acuosa permite reducir hasta un 0.22 (93.7\% de eliminación) y hasta 0.05 (98.6\%) cuando se aplica la difusión a partir de harina extraída.

Fibra total (FND). En el proceso b se confirma la reducción prevista en el contenido de fibras debido a la elimina: ción de las membranas. El contenido total en el proceso c aumenta debido a la purificación del producto por eliminación de sustancias solubles en el agua de lavado.

Proteína soluble $(\%, \mathrm{pH}=9)$. Los métodos de eliminación de clorogénico afectan seriamente la solubilidad de la proteína, propiedad deseable cuando el producto obtenido se pretende utilizar como aditivo, principalmente en bebidas. El procedimiento $b$ reduce la solubilidad de la proteína respecto al proceso acuoso, debido probablemente a la exposición durante $2 \mathrm{~h}$ a $60^{\circ} \mathrm{C}$. El método $\mathrm{c}$ afecta más seriamente a esta característica, a pesar de que el tiempo de contacto de la harina con el agua a elevada temperatura es mínimo; sin embargo hay que considerar que una vez 
transcurridos los diez segundos durante los cuales se agita la suspensión para extraer los compuestos fenólicos, la etapa de enfriamiento con agua a $15^{\circ} \mathrm{C}$ no es lo suficientemente rápida y se produce una desnaturalización que disminuye la solubilidad.

Digestibilidad. El coeficiente de digestibilidad aparente se midió por un método enzimático que implica la digestión con tripsina, quimotripsina y peptidasa y permite conocer el efecto de la pérdida de digestibilidad por desnaturalización térmica o por la reacción con los polifenoles. Los coeficientes de digestibilidad aparente (CDA) reflejan la presencia de ácido clorogénico en la harina. Las condiciones extremas $\left(T=100^{\circ} \mathrm{C}\right)$ empleadas durante el proceso $c$ no se reflejan en la calidad de la harina, lo que puede deberse a la ausencia de clorogénico que eleva los valores del CDA. Sin embargo la reducción sufrida en el porcentaje de solubilidad de la proteína, junto con el aumento en el CDA, puede atribuirse a una desnaturalización. El extremo desplegamiento molecular supone, por una parte, la ruptura de puentes disulfuro, la pérdida de capacidad de imbibición de agua y una diferente reactividad, lo que explica la pérdida de las propiedades funcionales y cambio en propiedades físicas y químicas (Kabirullah y Wills, 1988). Sin embargo la desnaturalización suave tiende a aumentar el valor nutricional de las proteínas porque la susceptibilidad del ataque enzimático se ve aumentada por la modificación de la estructura ternaria de las proteínas, que las hace más digestibles (Gómez y Torre, 1989; Barry, 1989).

Tabla IV

Comparación de las características del producto proteíco obtenido por los distintos procedimientos de eliminación de ácido clorogénico

(\% en base seca desgrasada salvo * en base seca)

\begin{tabular}{lrrr}
\hline Características & Proceso a & Proceso b & Proceso c \\
\hline${ }^{*}$ Aceite residual & 54.59 & 54.96 & 57.27 \\
Ac. clorogénico & 0.41 & 0.22 & 0.047 \\
Proteína (N.6.25) & 63.57 & 66.14 & 67.01 \\
F.N.D. & 20.08 & 19.23 & 21.00 \\
F.A.D. & 10.14 & 9.83 & 10.75 \\
Cenizas & 5.36 & 6.69 & 6.87 \\
"Azúcares totales & 2.50 & 2.36 & 2.49 \\
Prot. soluble (pH=9,\%) & 87.36 & 85.24 & 78.31 \\
Digestibilidad (C.D.A.,\%) & 82.06 & 84.73 & 85.52 \\
Lisina disponible & 3.40 & 3.18 & 3.53 \\
(mg/1 6 g N) & & & \\
\hline
\end{tabular}

F.N.D.: celulosa + hemicelulosa + lignina

F.A.D .: celulosa + lignina

"extraídos con alcohol

Proceso a: Proceso acuoso (sin etapa de eliminación de comp. fenólicos).

Proceso b: Difusión de almendras cortadas a la mitad

Proceso c: Difusión de almendras molidas ya extraídas

Lisina disponible. La lisina disponible, que se reduce ligeramente en el proceso $b$ respecto al acuoso (a), es algo superior en el proceso c. Este comportamiento puede justi- ficar la menor disponibilidad de algunos aminoácidos cuando no se elimina el ácido clorogénico.

Color. Todos los productos obtenidos presentan un color claro a pH neutro. Los análisis a $\mathrm{pH}$ básico de una suspensión de harina 1:20 (p:v), tras una hora muestran que las harinas procedentes de los procesos b y $c$ presentan color blanco, mientras que los resultantes del proceso acuoso presentan color crema.

\section{CONCLUSIONES}

Los bajos porcentajes de extracción de aceite obtenidos a lo largo de todo el estudio se justifican por la eficacia limitada del sistema de separación centrífuga de las fases sólida y líquida.

Los:elevados valores del coeficiente de digestibilidad aparente obtenidos en todos los procesos indican que la realización de un proceso acuoso evita la desnaturalización térmica y la presencia de compuestos fenólicos y azúcares reductores. Estos compuestos, eliminados en la fase líquida, podrían causar reacciones con las proteínas, reduciendo la disponibilidad proteica y afectando al color del producto.

La realización del tratamiento acuoso aún sin etapas adicionales de eliminación de compuestos fenólicos (a) permite reducir sensiblemente el contenido de ácido clorogénico del producto sólido obtenido en casi un $90 \%$. La realización de una etapa de eliminación por difusión a partir de las almendras a la mitad (b) permite alcanzar porcentajes aún superiores. En el proceso donde se extraen de las almendras molidas semidesgrasadas (c) se alcanza todavía una mayor eliminación, debido a la serie de lavados a elevada temperatura que arrastran, además de compuestos solubles de bajo peso molecular, parte del aceite. La eliminación de las proteínas de menor peso molecular o más solubles es precisamente uno de los inconvenientes de este último proceso.

La incorporación de las etapas de eliminación de los compuestos fenólicos afecta principalmente a la acidez y número de peróxidos del aceite. El producto sólido resultante de los tres procesos propuestos posee un color claro, que lo hace apto como aditivo en productos para el consumo humano. La difusión del ácido clorogénico, debido a la exposición del producto a temperaturas superiores a las del proceso acuoso, supone una reducción en la calidad de la proteína.

Aunque el proceso de extracción acuosa de aceite de oleaginosas se propone como un proceso ecológico, presenta ciertos inconvenientes desde el punto de vista de la eliminación de corrientes residuales, con elevado contenido en materia orgánica. Los dos procesos que incorporan etapas de eliminación del ácido clorogénico producen un efluente con más materia orgánica, puesto que en el caso b se eliminan sustancias solubles (que difunden desde la almendra) y membranas, y del proceso $c$ se eliminan también sólidos en suspensión.

Aunque algunos procesos reciclan el suero de nuevo (como el proceso acuoso de Lanzani et al., (1983), que 
recircula un $50 \%$ a la etapa de batido), no se ha considerado aquí esta posibilidad, puesto que, como se ha podido comprobar, se elimina en dicho líquido la mayor parte del ácido clorogénico contenido inicialmente en las almendras. La utilización de fase líquida libre de estos compuestos favorece la difusión del mismo desde las almendras.

\section{BIBLIOGRAFIA}

Barry, J. L. (1989).-«L'influence des traitments technologiques sur la digestibilité des aliments".- Biofutur 62, 51-55.

Bau, H. M., Mohtadi-Nia, D. J., Mejean, L. y Debry, G. (1983).- «Preparation of colorless sunflower protein products: effect of processing on physicochemical and nutritional properties».- J. Am. Oil Chemists'Soc. 60 1141-1147.

Cruz Madueño, E. (1990).- «Extracción acuosa».- Aliment. Equipos Tecnol. 9, 51-58.

Dreher, M. L., Roath, W. W., Holm, E. T. y D'Appolonia, B. (1983).- «Yield, characteristics and composition of oil-type sunflower seed grown in North Dakota".-J. Am. Oil Chemists'Soc. 60, 1876-1877.

Elías, L. G., De Fernández, D. G. y Bressani, R. (1979).- «Possible effects of seed coat polyphenolics on the nutritional quality of bean protein".- $J$. Food Sci. 44, 524-544

Flemming, S. E. y Sosulski, F. W. (1977).- «The utilization of sunflower protein in milk-like beverages».- J. Inst. Can. Sci. Technol. Aliment. 10 229-232.

Gómez P., J. M. y Torre B., Ma . C. (1989) - «Influencia de la tecnología en e valor nutritivo de los alimentos. I: Proteínas».- Alimentaria 26 , 15-21.

Hagenmaier, R., Cater, C. M. y Mattil, K. F. (1973).- «Aqueous processing of fresh coconuts for recovery of oil and coconut skim milk».- J. Food Sci. 38, 516-518.

Hagenmaier, R. D. (1974).- «Aqueous Processing of full-fat sunflower seeds: yields of oil and protein".- J. Am. Oil Chemists'Soc. 51, 470-471.

Helrich, K. (Ed.). (1990).- Official Methods of Analysis of the Association of Official Analytical Chemists.- 15th ed. Published by A. O. A. C. Inc. Virginia (USA).

Hron R. J. Sr., Koltun S. P., Graci A. V. Jr. (1982).- «Biorenevable solvents for vegetable oil extraction».- J. Am. Oil Chemists'Soc. 59, 674A-682A.

Hsu, H. W., Vavak, D., Satterlee, L. D. y Miller G. A. (1977).- «A multienzyme technique for estimating protein digestibility».- J. Food Sci. $\mathbf{4 2}$ 1269-1273.

Hurrell, R. F. y Finot, P. A. (1985).- «Efects of food processing on protein digestibility and amino acid availability" in "Digestibility and amino acid availability in cereals and oilseeds". Chap. 8.- J. W. Finley y D. T. Hop kins (Ed.).- Am. Assoc. of Cereal Chemists, Inc., St. Paul (Minnesota).

James, N. A. y Ryley, J. (1986).- «The rapid determination of chemically reactive lysine in the presence of carbohidrates by modified trinitrobenzensulphonic acid procedure». - J . Sci . Food Agric. 37, 151-156

Johnson, L. A., Lusas, E. W. (1983).- «Comparison of alternative solvents for oils extraction".- J. Am. Oil Chemists'Soc. 60, 229-242.

Kabirullah, M. y Wills, R.B.H. (1988).-«Foaming properties of sunflower seed protein".- J. Food Sci. Technol . 25, 16-19.

Kim, S. H. (1989).- «Aqueous extraction of oil from palm kernel».- J. Food Sci. 54, $491-492$.
Lanzani, A., Petrini, M. C., Cozzoli, O., Gallavresi, P., Carola, C., Jacini G. (1975).-«On the use of enzymes for vegetable-oil extraction. A preliminary report".- Riv. Ital. Sostanze Grasse 52, 226-229.

Lanzani, A., Cardillo, M. y Petrini, M. C. (1979).- «Preparazione di concentrati proteici da semi di girasole per via umida».- Riv. Ital. Sostanze Grasse 56, 48-51.

Lanzani A., Camurati, F., Cardillo, M., Cortesi, N., Mariani, C., Fedeli, E., Ponzetti, A. y Pieralisi, G. (1983).- "Tecnologia di estrazione di farine a partire da semi di girasole. Nota II».- Riv. Ital. Sostanze Grasse 60, 353363.

Lanzani, A. Bondioli, P., Mariani, C. Fedeli, E. Ponzetti, A. y Pieralisi G. (1986).-«Tecnologia integrale di estrazione della sostanza grassa e di preparazione di farine dal frutto di avocado".- Riv. Ital. Sostanze Grasse 63, 487-492.

Lawhon, J. T., Rhee, K. C. y Lusas, E. W. (1981).- «Soy protein ingredients prepared by new processes-Aqueous processing and industrial membrane isolation».- J. Am. Oil Chemists'Soc. 58, 377-384.

Leung, J., Fenton, T. W. y Clandinin, D. R. (1981).- «Phenolic components of sunflower flour".- J. Food Sci. 46, 1386-1393.

Lin, M. J. Y., Humbert, E. S. y Sosulski, F. W. (1974).- «Certain functional properties of sunflower meal products".- J. Food Sci. 39, 368-370.

Lowry, R. R., Tinsley, I. J. (1976).- «Rapid colorimetric determination of free fatty acids".- J. Am. Oil Chemists'Soc. 53, 470-472.

Marek, E., Schalinatus, E., Weigelt, E., Mieth, G., Kerns, G. y Kude, J. (1990).- "On the aplication of enzymes in the production of vegetable oil».- Prog. Biotechnol. 6, $471-474$

Nagel, C. W., Herrick, I. W. y Graber, W. R. (1987).- «Is chlorogenic acid bitter?".-J. Food Sci. 52, 213.

Pomenta, T. V. y Burns, E. E. (1971).- «Factors affecting chlorogenic, quinic and caffeic acid levels in sunflower kernels".- J. Food Sci. 36, 490-492.

Raheja, R. K., Kaur, C., Singh, A. y Bathia, I. S. (1973).- «New colorimetric method for quantitative estimation of phospholipids without acid digestion".- J. Lipid Res. 14, 695-697.

Rhee, K. C., Cater, C. M. y Mattil, K. F. (1972).- «Simultaneous recovery of protein and oil from raw peanuts in an aqueous system».- J. Food Sci. 37, 90-93.

Sabir, M. A., Sosulski, F. W. y Kernan, J. A. (1974a).- «Phenolic constituents in sunflower flour".- J. Agric. Food Chem. 22, 572-574.

Sabir, M. A., Sosulski, F. W. y Finlayson, A. J. (1974b).- «Chlorogenic acidprotein interactions in sunflower".- J. Agric. Food Chem. 22, 575-578.

Shamanthaka S., M. C. y Sastry, R. N. M. S. (1990).- Binding of chlorogenic acid by the isolated polyphenol-free $11 \mathrm{~S}$ protein of sunflower (Helianthus annuus) seed».- J. Agric. Food Chem . 38, 2103-2110.

Sodini, G. y Canella, M. (1977).- «Acidic butanol removal of color-forming phenols from sunflower meal».- J. Agric. Food Chem. 25, 822-825.

Sosulski, F. W., McClearly, C. W. y Solimán, F. S. (1972).- «Diffusion extracion of chlorogenic acid from sunflower kernels".- J. Food Sci. 37, 253256.

Sosulski, F. W., Sabir, M. A. y Fleming, S. E. (1973).- «Continuous diffusion of chlorogenic acid from sunflower kernels».- J. Food Sci. 38, 468-470.

Solsulski, F.W. (1979).-«Organoleptic and nutritional effects of phenolic compounds on oilseed protein products: a review».- J. Am. Oil Chemists'Soc. 56, 711-715.

(Recibido: Noviembre 1992). 